\title{
THE PYLGRIMS SEA-VOYAGE AND SEA-SICKNESS, POEMA MEDIEVAL DEDICADO \\ A LOS PEREGRINOS INGLESES CON RUMBO A COMPOSTELA. COMENTARIO Y TRADUCCIÓN AL ESPAÑOL
}

Pedro Jesús Marcos

Profesor Emérito

\section{A D. Emilio Lorenzo}

Deseo vivamente dedicar este artículo a la memoria de D. Emilio Lorenzo, personalidad fuera de lo común, por la que siempre he sentido respeto, gran afecto y una admiración inextinguibles. Hace apenas unos meses emprendió su vuelo hacia el misterio. Académico de la Real Academia Española e inspirador del establecimiento de la Filología inglesa en España, fundó dichos estudios en la Universidad Complutense de Madrid, que, junto con la de Salamanca, ha servido de referente para el resto de las universidades españolas. Su gran humanidad, atrayente y modesta al mismo tiempo, le hacen merecedor de toda clase de parabienes. Siempre mostró su generosidad, inagotable y a flor de piel, con elegancia y discreción. Cumplidor infatigable, aceptó con gusto sus responsabilidades profesionales hasta el último momento, a pesar de sus dificultades y limitaciones. Pasó por la vida sin demasiado ruido; no lo necesitaba. Bastaba llegar a comprenderle para que se fraguara un afecto y una devoción duraderos.

\section{RESUMEN}

Tomado de la edición de Frederick J. Furnivall, publicada en Londres en 1867 para la E.E.T.S., me ha parecido oportuno, por razones que no vienen al caso en este momento, traer a colación este poema inglés de la lejana época de las peregrinaciones medievales a Compostela. Se inicia este trabajo con una breve referencia a la historiografía relativa al sepulcro del apóstol Santiago y a algunos famosos peregrinos ingleses a Compostela, como Margery Kempe, una devota y notable peregrina del siglo XIV, o como William Way del siglo XV, autor de Itineraries, en el que cuenta sus variadas peregrinaciones, o Andrew Boorde, siglo XvI, autor de The first book of the introduction of Knowledge, la primera guía para viajeros 
escrita en inglés, o como, finalmente, Walter Starkie, contemporáneo nuestro y autor de The Road to Santiago. Después de situarlo en su contexto histórico cultural, se presenta el manuscrito en el que se encuentra el poema que ha suscitado mi interés. Sigue un comentario que abarca algunos aspectos de su ortografia, el modelo de estructuración morfosintáctica y la forma de composición utilizada por el autor. Por último, se ofrece una traducción quasi literal de dicho poema, acompañada de una interpretación que incluye la intención del autor y del público al que iba destinado.

La historiografía relativa al sepulcro de Santiago es, ciertamente, abundante, aunque su fiabilidad, por tratarse de hechos enormemente controvertidos, queda a menudo en entredicho. Asimismo, los testimonios más antiguos que tratan de establecer y demostrar la predicación de Santiago en la España romana son, además de escasos, pobres en la aportación de datos y detalles convincentes. No obstante, no se puede negar que existan referencias a estos hechos, mezcla evidente de historia y de leyenda. Tales son los casos, por citar dos ejemplos, de los célebres Comentarios al Apocalipsis del Beato de Liébana del siglo VIII y el breve poema, escrito en latín por el abad de Malmesbury, San Adhelmo (709), en el que dice de Santiago:

Primitus Hispanas convertit dogmate gentes.

Esto demuestra, únicamente, que el rumor, o noticia, si se quiere, había llegado en fecha temprana a los lejanos confines de la Inglaterra medieval. También Beda el Venerable recoge ese mismo rumor en su Historia eclesiástica del pueblo inglés.

Por otra parte, La Crónica viene a ser el primer texto narrativo de carácter histórico que hace una clara alusión al sepulcro de Santiago. Se dice en él que en el año 872 Alfonso III había ordenado derribar la pequeña iglesia levantada allí por Alfonso el Casto para, en su lugar, construir otra de sillería y cemento con columnas y basamentos de mármol, de gran belleza, España sagrada, t. 14, pág. 439. El primer documento cuya autenticidad admite el erudito Barrau Dihigo en su trabajo Ëtudes sur les actes des rois asturiens (719-910) es del año 885 y en él se alude también al sepulcro de Santiago.

Hay documentos históricos españoles en los que se encuentran referencias claras a las peregrinaciones a Santiago de Compostela. E1 25 de julio del año 893 el rey Alfonso III hace donación de Arcos y sus posesiones al apóstol Santiago: 
...pro sustentatione religiosorum fratrum in vita sancta perseuerantium seu peregrinorum ibi advenientium.

Dos años más tarde, el 25 de noviembre, hace nueva donación al Apóstol de unas propiedades en el Bierzo con los mismos fines que la anterior. Parece que queda clara, al menos, la alusión al hecho concreto de la peregrinación al sepulcro de Santiago y la existencia de una comunidad de monjes. El mencionado rey vuelve a hacer uso de la misma fórmula documental en la donación que hace de unas villas que se encuentran en territorio de Coimbra, que acababa de conquistar. Pero al poner la fecha (30-12 de 898) hace constar:

...in die festivitatis supradicti patron nostri sci lacobi III kals. Ianuarias.

Lo cierto es que la difusión del descubrimiento del supuesto sepulcro de Santiago por toda la cristiandad se produjo a través de los martirologios y también al hecho comprobado de que Francia jugó un papel muy importante en la promoción, no exenta de intereses, del culto jacobeo. Francia no sólo creó y puso a disposición de los peregrinos una notable red de rutas de peregrinación, hostelerías y hospitales, sino que fomentó activamente la formación de numerosos contingentes de peregrinos a Compostela. Hay que admitir, por tanto, que la eficaz contribución de los monjes de Cluny fue decisiva, hasta el punto de que sin ellos resultaría muy difícil de comprender, y menos aún de justificar, aquel vasto movimiento de la cristiandad a favor de las peregrinaciones a Santiago.

Podría decirse que lo que comenzó siendo un movimiento más o menos espontáneo, se convirtió de alguna manera en asunto de estado durante los reinados de Sancho el Mayor y Alfonso VI y las actuaciones de los obispos Diego Peláez y Diego Gelmírez, quienes, con la colaboración de la poderosa Orden de Cluny y de varias instituciones hospitalarias - sujetas a la obediencia de la regla de San Agustín- encauzaron y fomentaron, movidos en parte por la fe y en parte por intereses de estado, esa corriente espontánea que atrajo a gentes de los más variados pueblos de la cristiandad, como se recoge en un extenso párrafo del famoso Codex Calixtinus, atribuido al Papa Calixto II, monje benedictino de Cluny, en realidad el conde Guido de Borgoña, emparentado con la casa de Castilla por el matrimonio de su hermano Raimundo de Borgoña con la infanta doña Urraca. En el libro I, XVII se encuentra una larga enumeración de las nacionalidades de los peregrinos que acudían a Santiago, así como una brillante descripción del culto y de las ceremonias religiosas que allí se celebraban. Sólo reproducimos las pocas líneas que interesan para este estudio. En ellas se dice: 
Llegan de todos los climas del mundo francos, normandos, escoceses, irlandeses, del país de Gales, teutones, gascones, navarros, vascos,

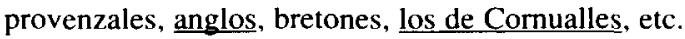

Y continúa diciendo el autor:

No puede contemplarse sin maravilloso gozo el espectáculo que ofrecen los coros de peregrinos velando en torno al venerado altar del bienaventurado Jacobo.

El entusiasmo desbordante del escritor, quienquiera que fuere, es más que evidente, pero también lo es la referencia a Compostela. Parece que dicho códice fue escrito hacia la segunda mitad del siglo XII, aunque es poco probable que lo hiciera el Papa Calixto II. En cualquier caso, coincide su aparición con uno de los períodos estelares de la cristiandad que levantó las grandes catedrales y monasterios medievales. Coincide también con el vigoroso impulso dado por los cluniacenses a las peregrinaciones. A ellos se debe la construcción de una amplia red de albergues y hospitales a lo largo de las rutas de peregrinación. Finalmente, consiguieron para Santiago de Compostela los mismos privilegios de que gozaba el Año Santo de Roma, es decir, el gran jubileo y la indulgencia plenaria.

Como acabamos de ver en la descripción contenida en el Codex Calixtinus, también los ingleses se sumaron al gran movimiento cristiano de la peregrinación a Compostela. Bastante menos importante y numerosa que la francesa, no por ello dejó de tener una amplia repercusión en Inglaterra. Es un hecho históricamente probado que gran número de iglesias anteriores al siglo XVI estaban consagradas al Santo de Compostela, aunque de muchas de ellas haya desaparecido la iconografía, es decir, la imagen del santo en traje de peregrino y las conchas marinas símbolos de la peregrinación compostelana. Recuérdese la pervivencia en Inglaterra del nombre mismo de Santiago, Saint James en inglés, en lugares como el parque de St James en Londres y el símbolo mismo de la monarquía británica que sigue asentándose en lo que ellos llaman St. James Court, porque el palacio de los Tudor en los alrededores del viejo Londres se construyó sobre una leprosería consagrada al apóstol Santiago. Quizás el monumento máximo del culto a Santiago en Inglaterra fuera la famosa Abadía de Reading que quedó completamente arrasada durante el reinado de Enrique VIII. Hoy sólo queda una pequeña iglesia católica dedicada al Apóstol, construida modernamente en el recinto de la antigua abadía y al lado mismo de la cárcel de Reading, en la que Oscar Wilde escribió algunos de sus poemas más famosos, como el de De profundis, por citar un ejemplo. 
Procede añadir que, así como los testimonios documentales e históricos relativos al culto de Santiago son relevantes en la historiografía inglesa, no se puede decir lo mismo cuando se trata de testimonios literarios. En la literatura medieval inglesa son, en realidad, escasos. Cabría conjeturar que, quizás, entre los numerosos peregrinos ingleses, escoceses e irlandeses que vinieron a Compostela, era más fácil encontrar a un alto dignatario de la Iglesia, o de la nobleza, que a un escritor. En cualquier caso, éstos mostraron poco entusiasmo por la Ruta Jacobea. Ocurre, por otra parte, que la literatura inglesa, escrita ya en inglés y no en latín, floreció más tarde. El abandono del latín como medio preferente de expresión literaria, y su sustitución por la lengua vernácula, representa un cambio radical de actitudes y de mentalidad frente a la Iglesia, al Estado y sus instituciones y a la misma sociedad de aquella época. Hasta entonces, latín e Iglesia habían estado perfectamente identificados. Con la aparición del nuevo espíritu, la Iglesia y su soporte linguístico pierden su hegemonía. Cabe añadir que la Iglesia había perdido también gran parte del enorme prestigio que había ido acumulando durante los siglos anteriores, convirtiéndose, al igual que otras instituciones del Estado, en objeto de duras críticas, tal como aparecen recogidas en las obras de los grandes escritores del momento, especialmente Langland en Piers Plowman y Chaucer en The Canterbury Tales, por citar algunos de los poemas más representativos. Iguales tendencias aparecen en la prosa, como puede apreciarse en la de un Wicliffe, aun cuando florecieran también creaciones poéticas de orientación piadosa de igual o mayor belleza y mérito literario, como puedan serlo Pearl, Patience y Cleenness.

Una de las primeras menciones a Santiago, como apóstol de España, es la que hace el anglosajón Saint Aldhelm (San Andelmo) a finales del siglo VII y principios del VIII. Fue abad de la abadía de Malmesbury y obispo de Sherborne y, aunque San Isidoro no lo cita en sus obras, este remoto abad inglés dedicó una inscripción en latín, ya citada, en la que proclama que Santiago fue:

\section{Primitus Hispanias convertit dogmate gentes.}

Otro anglosajón, Beda el Venerable, confirmaba la misma creencia en su ya mencionada Historia eclesiástica del pueblo inglés (732), cuando todavía no se había descubierto el sepulcro de Santiago en Galicia, ni existía, por consiguiente, la peregrinación.

Si aceptamos la interpretación que propone Ernesto de Orden Miracle, de un verso contenido en el famoso poema narrativo de finales del siglo XIV, conocido bajo el nombre de su héroe, Bruce, tendríamos que incluirlo entre las manifestaciones literarias británicas relacionadas con el apóstol Santiago. 
Por otra parte, se trata de un largo poema narrativo de 13.549 versos, que el propio autor, John Barbour, fecha en 1375. Está escrito en versos octosilábicos rimados y dispuestos en forma de pareados. Es, por otra parte, un ejemplo de poesía escrita en el dialecto del norte de Inglaterra. En él se cuenta la vida y proezas del héroe nacional escocés Robert Bruce, que fue también rey de Escocia. Para el autor se trata de un romance histórico. Sigue, en efecto, los hechos históricos con bastante fidelidad. Cabe decir, no obstante, que su arrebatado patriotismo llega a alejarle a veces de la verdad histórica. El primer libro es un canto a la independencia frente a los ingleses. Es desde el punto de vista literario una obra de arte. Contiene, además, todos los ingredientes propios de las obras destinadas a provocar sentimientos nacionalistas y, por eso, entre otras cosas, no es fácil relacionarlo con el Apóstol Santiago. Veamos ahora la interpretación de Ernesto de Orden, tal como aparece en su documentado e interesante libro Santiago en América y en Inglaterra y Escocia, pág. 42.

Según las crónicas de la época y, también, el mencionado poema, el rey escocés Robert Bruce había prometido ir a luchar contra los musulmanes. Viendo que se le acercaba la hora de la muerte sin haber cumplido esta promesa, llamó a sus hombres de armas y les manifestó su deseo de que, una vez muerto, le sacaran el corazón y lo llevaran con ellos a la guerra de Tierra Santa o a España. El valeroso y temible Sir James Douglas cumplió el deseo de su rey. Muere éste y Douglas se lleva, en efecto, el corazón del legendario Robert Bruce en una cajita de plata colgada del cuello. Llegados a Sevilla en 1330, el rey Alfonso XI de Castilla le confió el mando de la vanguardia en una peligrosa acción contra los moros. Douglas muere en el combate. Para conectar esta magnífica epopeya en verso con la peregrinación a Santiago, Ernesto de Orden se basa en un solo verso que aparece en la descripción que hace el autor del tormentoso viaje por mar desde Berwick hasta desembarcar en Sevilla. Dicho verso dice así:

He salit and left the grund of Spanie.

Y argumenta:

Si la palabra grund se interpreta como el ground, la tierra de España, poco podríamos conjeturar, pero si se interpreta como Grunn o Groun que es como se llamaba el puerto de la Coruña en los documentos británicos de la época, resultaría que Douglas pisó tierra en Galicia y parece lógico que compareciera, con el corazón de su rey ante las reliquias de su Patrón Santiago. 
En el mismo sentido se pronuncia James S. Stone en su obra The Cult of Santiago.

Creemos que esta interpretación difícilmente se puede sostener sobre tan débil argumento. El poema Bruce se escribe en la segunda mitad del siglo XIV en el que, como ya se ha señalado, el fervor religioso había decaído considerablemente. No existe ninguna alusión que nos permita asegurar que el autor del poema sintiera interés alguno por el hecho de la peregrinación compostelana. No es imposible, incluso, que desconociera su existencia. Y si la conocía, sería más bien desde una perspectiva bélica, puesto que, lo mismo que Jerusalén, España era un país en lucha contra los sarracenos y ese espíritu combativo era el que realmente atraía el interés de caballeros y guerreros, comprometidos en la recuperación tanto de los Santos Lugares, mediante las Cruzadas, como de la España musulmana, a través del largo período de la Reconquista. Lingüísticamente hablando, resulta todavía más difícil mantener en pie dicha interpretación, dado que la palabra grund en el inglés medio significaba también los fondos del mar, acepción que, en mi opinión, encaja perfectamente, dada la existencia de zonas de aguas profundas en la ruta que debió de seguir Sir James Douglas en su navegación hacia Sevilla, su verdadero punto de destino.

Aceptamos, no obstante, que la interpretación de Stone, compartida por La Orden no carece de belleza, ni de un cierto toque de romanticismo, y, también, que puede que la nuestra sea tan débil como la que acabamos de comentar brevemente.

El poema medieval inglés que traemos a colación ahora fue compuesto para peregrinos que se dirigían a Compostela desde Inglaterra. La referencia es directa y aparece ya en la primera estrofa:

That saylen to seynt Jamys,

Puesto que ni el tema ni la ocasión permiten mayor liberalidad en el empleo del tiempo y del espacio concedidos, limitaremos al mínimo las referencias a algunos detalles de conocidos peregrinos ingleses cuya presencia en Santiago está perfectamente documentada. Se trata de personajes notables en más de un aspecto. Hay caballeros, nobles, eclesiásticos y, naturalmente, el pueblo llano, que constituye mayoría. De entre éstos los hay tan singulares y atrayentes para muchos como pueda serlo una tal Margery Kempe, Burnham de soltera y nacida en King's Lynn en 1373, devota y visionaria, y con una personalidad arrolladora no exenta de mansedumbre. Viajera infatigable, peregrinó por toda Europa y por Tierra Santa. En julio de 1417 llegaba a Compostela. Cabría preguntarse si no hizo bueno, en algún momento de su vida, el dicho aquel de que Qui multum peregrinantur raro sanctificantur. 
Con el beneplácito del rey Enrique VI de Inglaterra, William Way, profesor del Exeter College de Oxford, inicia una serie de peregrinaciones que contaría más tarde en sus Itineraries. Salió de Eton el 25 de marzo de 1456, pero no embarcó en el Mary White que zarpaba desde Plymouth rumbo a Grwne (La Coruña) haste el 17 de mayo. Devoto y respetuoso con las formas de la tradición compostelana, puede decirse que cumplió honradamente con los modos que caracterizaban al verdadero peregrino.

En cambio, sería aventurado atribuir igual actitud a otro distinguido peregrino inglés llamado Andrew Boorde, hombre de talento y afamado médico de su tiempo. Vivió en una época completamente distinta a la que había conocido William Way, como muy distintas fueron también las circunstancias de sus vidas. Corrían otros tiempos. Se había producido el cisma de Inglaterra, y los escritos de Erasmo circulaban ya por toda Europa. Es autor de la primera guía para viajeros escrita en inglés y publicada hacia 1547 bajo el título: The First Book of the Introduction of Knowledge. Como cabía esperar de un hombre de tan notable formación científica, se muestra muy crítico respecto a muchos de los problemas sociales de su época, como haría más tarde al referirse a Compostela, que visitó hacia el año 1532 y, años más tarde, por segunda vez. Lejos habían quedado el fervor y el entusiasmo de los peregrinos de los primeros siglos. La impresión que del Camino de Santiago nos ha dejado en su libro es bastante negativa, pues parece que no encontró en España más que peligros tremendos, penalidades sin fin, frío, hambre, ladrones y gente de mal vivir. Desgraciadamente, hemos de admitir que no le faltaba objetividad al tal doctor, pues no fue el único, ni mucho menos, en denunciar tales condiciones, de las que difícilmente puede dudarse, puesto que numerosas fueron también las medidas adoptadas por los reyes, algunas de ellas severísimas, para proteger a los peregrinos que osaban adentrarse por la ruta de Santiago. En cualquier caso, es otra forma de medir el grado de atracción que debió ejercer la peregrinación compostelana en las mentes medievales y lo mucho que de ella esperaban conseguir sus devotos, que no dudaban en acudir desde los rincones más alejados de Europa.

Sería imperdonable no mencionar aquí a uno de los más populares peregrinos ingleses contemporáneos: Walter Starkie. Director del Instituto Británico, fue profesor en la Facultad de Filosofía y Letras de la Universidad Complutense de Madrid en la que impartió cursos de literatura inglesa en los años 50. Sus discípulos guardan de él un recuerdo imborrable de las clases magistrales que dio sobre la figura inagotable del inmortal Shakespeare, objeto a su vez del culto particular que se le rinde año tras año en su Stratford-on-Avon natal. Buen conocedor de España, por sus prolongadas estancias, y fruto de sus viajes y peregrinaciones a Compostela, escribió un libro titulado The Road to Santiago, que se 
publicó en Londres en 1957. Vale la pena leerlo. Tres años más tarde aparecería el libro de T.D. Kendrick, director que fuera del Museo Británico, bajo el título Saint James in Spain. Se trata de un libro muy distinto del anterior. Predomina en él la erudición, mientras que en el otro prevalece el corazón. Su lectura es también interesante, ilustrativa y provechosa, aunque la visión que ofrece de la cuestión difiere considerablemente de la de su contemporáneo W. Starkie: dos británicos, la misma época, y dos puntos de vista diferentes sobre un mismo tema.

\section{El MANUSCRITO}

El texto que hemos utilizado es el editado por Frederick J. Furnivall, y publicado en Londres en 1867 para la Early English Text Society.( E.E.T.S.). En este volumen, el número 25 de dicha colección, Furnivall recoge las obras que se indican a continuación.

The Stations of Rome, en versión versificada, tomada del Manuscrito Vernon que, se supone, debió ser escrito hacia 1370, y otra en prosa, más tardía, procedente del Manuscrito Porkington, N.10, que se estima debió escribirse entre los años 1460 y 1470. Las diferencias ortográficas, morfosintácticas e, incluso, estilísticas, en algunos casos, entre ambas versiones son, como cabía esperar, bastante notables.

A continuación viene el poema que nos ha interesado para esta ocasión. Se titula Pilgrims Sea-Voyage and Sea-Sickness, y se encuentra en el Manuscrito R.3, 19, de la Biblioteca del Trinity College de Cambridge. Por último, aparece otro poema titulado Clene Maydenhod, tomado del Manuscrito Vernon, que se encuentra en la Bodleian Library de Oxford. La inclusión de este último poema, que el propio Furnivall considera A Supplement to Hali Meidenhood, la explica el autor mediante las siguientes palabras:

The cause of Clene Maydenhod appearing in this Text is Mr. Cockayne's edition of that most vivid sketch of an English girl's forsake marriage and matemity in 1220, Hali Meidenhod.

Y añade:

...seeing that Clene Maydenhod was in the Vernon, I could not resist the temptation of printing it, for illustration and contrast sake.

Sabemos que lo que Furnivall deseaba era editar estos poemas en sus versiones más antiguas. Se da la circunstancia de que William M. Rossetti los había editado anteriormente, también para la E.E.T.S., pero a partir de los Ma- 
nuscritos Cotton y Lambeth, textos tardíos que, según se estima, debieron redactarse hacia 1445, o en los primeros años de la segunda mitad del siglo XV. Coinciden, pues, con la época del infortunado Enrique VI de Inglaterra, el último rey inglés de la casa de Lancaster, hijo del famoso Enrique V, el vencedor de la decisiva batalla de Agincourt, de tan profundo significado para el orgullo nacional inglés, y a quien Shakespeare inmortalizó en su Henry $V$, seguramente el más patriótico del ciclo de sus dramas históricos. Totalmente incapaz de cumplir la alta misión de reinar a la que le obligaba su destino, Enrique VI de Inglaterra puso todo su interés en las prácticas piadosas y en la fundación de instituciones docentes. A él se deben la fundación del Eton College en 1440 y la del King's College de Cambridge en 1447. Se sabe que el manuscrito de referencia se redactó durante su reinado. Este desdichado monarca muere a manos del verdugo en la siniestra Torre de Londres el 21 de mayo de 1471 , por orden del duque de York, su hermano, que se había proclamado rey de Inglaterra con el nombre de Edward IV el 29 de marzo de 1461. El reinado de Enrique VI terminó con dicha proclamación. El manuscrito de Cambridge se compuso durante su reinado (1422-1461). Esta última es, pues, una versión del siglo XV.

Como dato curioso cabe mencionar el hecho de que la paginación del volumen 25 de la E.E.T.S. no es correlativa. El propio editor nos dice que decidió mantener la misma paginación que estos tres poemas tienen asignada en los manuscritos de origen, a fin de facilitar el acceso a ellos de forma inmediata.

\section{COMENTARIO}

Esta canción marinera es, probablemente, la más antigua en lengua inglesa y su inclusión la justifica Furnivall con las siguientes palabras:

The allusion to the sea-voyage to the Holy Land in the Stations has induced me to add to this text the most amusing poem on The Pilgrims Sea-Voyage and Sea Sickness from the MS. Trin., R.3, 19.

(La alusión al viaje marítimo a Tierra Santa en las Estaciones me ha inducido a añadir a este texto uno de los poemas más divertidos sobre los viajes por mar y lo mal que se pasaba (MS. Trin. R. 13, 19.)

If men wuste. grete and smale te pardoun tat is at grete Rome. bei wolde teller. In heore dome. Hit were no need. to mon in cristiante. To passe in to te holy fond. Ouer te see. to Jerusalem. ne to Kateryne. 
(Si la gente supiera, importante y humilde por igual, del perdón que se alcanza en Roma la excelsa, lo dirían en casa. El hombre de la cristiandad no necesita viajar a Tierra Santa por mar, ni a Jerusalén, ni a Santa Catalina.)

Furnivall califica este poema de most amusing y es evidente que esa fue la intención de quien lo compuso. No parece demasiado aventurado suponer que esta canción marinera se cantara o recitara en las posadas de los distintos puertos en los que se concentraban los peregrinos, o incluso en los mismos barcos antes de zarpar. Inevitablemente nos viene a la memoria la llegada de Chaucer a la $T a$ bard Inn with full devout corage. Es posible, también, aunque poco probable, por aquello de que nadie escarmienta en cabeza ajena, que más de un peregrino desistiera de su propósito inicial después de oír la serie interminable de calamidades que les esperaba. Cabe añadir, finalmente, que las perspectivas de un viaje y sus expectativas pueden llegar a provocar, salvo excepciones, entusiasmos desmedidos que, no pocas veces, terminan en decepción, cuando no en fracaso.

Tampoco es difícil imaginar el bullicio y la algazara de los peregrinos comiendo y bebiendo alegremente, riéndose con los chistes y las mil historias que cuentan unos y otros, mientras algunos matan el tiempo jugando antes de embarcar. Por eso, el poeta narrador les advierte, ya desde el primer verso, que tendrán que olvidarse de todo ese jolgorio:

\section{Men may leue alle gamys,}

Parece, en principio, que ése es el mejor consejo que puede darse a unos peregrinos que, se supone, van por vez primera en busca de la remisión de sus pecados mediante las indulgencias plenarias o el jubileo. Pero antes han de pasar por la penitencia que, sin duda, van a cumplir con todo rigor, pues les va a llegar por las vías más variadas:

- El ruido. El rugido de la mar y los crujidos de la embarcación por un lado y, por el otro, la inacabable letanía de las voces de mando, que se dan una y otra vez, nada menos que en cuatro estrofas $(2,3,4$ y 5$)$, de las 9 que forman el poema.

- El mareo, con todas sus manifestaciones: aversión a la comida y a la bebida, vómitos, dolores de cabeza, etc.

Peores son, seguramente, las burlas y las bromas pesadas de que son objeto por parte de los marineros, que intentan distraer así a los peregrinos, pues, antes de que llegue la noche, más de uno estará mareado y gimiendo:

For som ar Iyke to cowgh and grope, (verso 23) 
- Las referencias a la comida y a la bebida (versos 26, 27 y 30), cuando se sabe muy bien que mencionarle la comida o la bebida a un pasajero que se marea en una embarcación es como mencionar la soga en casa del ahorcado. Pero eso sí, que no se diga que se les niega e1 pan y la sal, (verso 39). Y, para colmo, que se les acerque un marinero para hacer comentarios sobre lo bien que navega el barco:

...O se howe welle owre good shyp sayles (verso 35)

Pero, quizás, la peor broma sea la de anunciarles que se les echa encima una borrasca, después de haberles invitado a que se alegren:

...be mery (verso 41 )

justo cuando los pobres peregrinos tienen el estómago en la boca:

haue theyr bowlys fast theym byt, (verso 46)

- Finalmente, la actitud del patrón frente a los padecimientos de los pasajeros. De su barco sólo le interesa comprobar que todo está en regla:

to see alle thyng be welle (verso 60 )

y que se le presta toda la atención posible. Ordena que venga el carpintero a repasar cualquier fallo que pueda haber, y a realizar las reparaciones necesarias aquí y allá, incluyendo también los pequeños desperfectos de las cabinas (versos 61, 63 y 64). Nada le importan, en cambio, las tremendas incomodidades que tienen que soportar los peregrinos de cuya asistencia y bienestar es, sin duda, el primer responsable.

Las desventuras y sinsabores que va a causarles la travesía serán su verdadera penitencia; una penitencia que, además de real, es inevitable y ajena a la voluntad de los propios penitentes. De ahí que la ironía del autor haya que buscarla también en el contexto social de la época. La corriente materialista y mundana de los últimos siglos de la Edad Media y el declinar de la autoridad espiritual de la Iglesia se ponen claramente de manifiesto en las peregrinaciones de la época. Conviene recordar, no obstante, que la idea de peregrinación tenía entonces un sentido mucho más amplio que el que se le fue atribuyendo posteriormente, hasta quedar restringido al marco del sentimiento religioso y sus manifestaciones. Entonces, como ahora, no todos los participantes en una peregrinación emprendían el camino movidos meramente por afanes de peni- 
tencia. Entonces, como ahora, las motivaciones eran variadas, como variados eran los personajes, cuya diversidad iba desde el más piadoso de los mortales, como es el caso de Margery Kempe, por ejemplo. A este efecto - y a muchos otros, por supuesto- podrían considerarse los Cuentos de Canterbury como el prototipo de peregrinación en sentido amplio. Es indudable que tanto el viaje como el lugar santo de destino proporcionaban al peregrino sobradas ocasiones para la meditación y el examen de conciencia. Sin embargo, está muy claro también que no todos los peregrinos de Canterbury dan muestras de tomarse el asunto demasiado en serio. Más bien parecen tomarse la peregrinación como si de unas vacaciones se tratara, dando rienda suelta a esa joie de vivre con la que suele recibirse a la primavera. De esta nueva actitud frente a la vida surgía el impulso de viajar hacia los santos lugares, generalmente fuera de Inglaterra. Así, los primeros versos del Prólogo contienen una clara alusión, cargada de ironía, de hasta qué punto había cambiado, en las postrimerías de la Edad Media, el espíritu de las primeras peregrinaciones.

Pero, si nos atenemos a la imposibilidad de penetrar hasta los más recónditos rincones del alma humana, cómo podremos asegurar, fuera de las creaciones literarias y sus manifestaciones, cuáles eran los verdaderos sentimientos y motivos que impulsaban a los peregrinos a arrostrar tantas dificultades, sufrimientos y sinsabores con riesgo, algunas veces, hasta de la propia vida. No obstante, tampoco sería razonable pensar que todos los peregrinos se movían impulsados únicamente por el gusto de la aventura. Tendremos que admitir que, junto al aventurero, se encontraba también el individuo firmemente convencido de sus creencias, por las que estaba dispuesto a aceptar cualquier sacrificio con tal de adecuar a ellas su conducta, no faltando tampoco aquellos que trataran de compatibilizar la devoción con la diversión.

No se puede negar que la impresión dominante que se obtiene de la lectura del General Prologue de Chaucer es la de que la sociedad medieval de su época era ya una sociedad materialista, en la que importaba más el «tener» que el «ser» y en la que la Iglesia daba muestras de haber claudicado frente al poder del dinero. Sin embargo, en el espléndido cuadro que Chaucer nos dejó de aquella sociedad, no se excluye la presencia de personajes, como el clérigo y el caballero, que se alzan en defensa de los valores espirituales frente al materialismo de entonces y al hedonismo que impregna la conducta humana.

Numerosas son las publicaciones históricas que avalan, en términos generales, la genial pintura que Chaucer hizo del ambiente social de su tiempo. Las peregrinaciones a Canterbury, por ejemplo, eran un agradable viaje en compañía, a veces, de personas interesantes, así como fuente de experiencias nuevas y diversión, al tiempo que proporcionaban un conocimiento directo de las gentes y lugares visitados, lo cual contribuía eficazmente a aliviar el tedio y la mo- 
notonía de la rutina diaria. La vida social de Kent y su paisaje, con su refrescante verdor abrileño, parece que resuena todavía con la alegre risa del simpático anfitrión (the host) quien, además, no tenía pelos en la lengua, así como la del monje (the monk) a quien le entusiasmaba la caza, o la viuda de Bath con su cara colorada y sanota, sus medias color escarlata, su audacia y un buen número de peregrinaciones en su haber. De ella nos dice Chaucer:

And thryes hadde she been at Jerusalem,

She hadde passed many a straunge streem;

At Rome she hadde been, and at Boloigne,

In Galice at seint Jame, and at Coloigne.

(En Jerusalén tres veces había estado,

muchos mares había cruzado,

en Roma había estado y en Bolonia,

en Galicia, en Santiago y en Colonia.)

No puede afirmarse que la Iglesia creara las peregrinaciones, ni siquiera que las fomentara; más bien las padecía. Lo que sí hizo fue intentar orientarlas hacia objetivos que fueran, al menos, edificantes, pues no se puede ignorar que su doctrina al respecto se resumía en la frase citada anteriormente: Qui multum peregrinantur, raro santificantur.

Los dos lugares de peregrinación más importantes para los cristianos eran entonces Jerusalén y Roma. En tercer lugar, y muy por encima de Canterbury y de Tours, estaba Santiago de Compostela. El propio Dante, en sus comentarios al soneto 33 de su obra Vita Nuova rinde tributo a Compostela y menciona a los peregrinos, en sentido general (los que abandonan su lugar de nacimiento) y en sentido especial (los que se dirigen a / o vuelven de la Casa de Santiago) agrupándoles bajo tres denominaciones:

Palmieri ( palmers, en inglés), son aquellos que viajaban a Tierra Santa de donde a menudo volvían con una rama de palmera.

Peregrini eran, para Dante, los que viajaban a Compostela,

Romei ( romers, en inglés), los que se dirigían a Roma.

En All's Well that Ends Well vemos cómo Helena decide abandonar Florencia para convertirse en peregrina a Santiago, aunque sabemos por Shakespeare que no consiguió llegar.

Recordemos también que, a pesar de la conmoción social y religiosa que supuso la Reforma, todavía resonaba por las grandes rutas de Alemania la Canción de Santiago. 
Finalmente, traemos también a colación el hecho de que la profesora King tradujo al latín el Gran Himno de Santiago, del cual existe una versión francesa cuyos dos últimos versos del estribillo dicen:

Qu' en Paradis nous puissions voir

Dieu et Monsieur Saint-Jacques.

\section{EL TEXTO}

The pylgrims sea-voyage and sea-sickness

Men may leue alle gamys,

That saylen to seynt Jamys!

Ffor many a man hit gramys

$4 \quad$ When they begyn to sayle.

Ffor when they haue take the see, At Sandwyche, or at Wynchylsee. At Brystow, or where that hit bee

8 Theyr hertes begyn to fayle.

Anone the mastyr commaundeth fast

To hys Shyp-men in alle the hast,

To dresse hem sone about the mast,

12 Theyr takelyng to make.

With « howe! hissal « then they cry, «

What, howe, mate! thow stondyst to ny,

Thy felow may net hale the by;»

16 Thus they begyn to crake.

A boy or tweyn Anone up styen, And ouerthwart the sayle-yerde lyen; «Y how! taylia!» the remenaunt cryen,

20 And pulle with alle theyr myght. «Bestowe the boote, Bote-swayne, anon, That our pylgryms may pley theron; For som ar lyke to cowgh and grone

24 Or hit be full mydnyght.»

«Hale the bowelyne! now, vere the shete!

Cooke, make redy anoon our mete,

Our pylgryms haue no lust to ete, 
28 I pray god yeue hem rest! « "Go to the helm! what, howe! no nere!

Steward, felow! A pot of bere!»

«Ye shalle have, sir, with good chere,

32 Anon alle of the best. «

«Y howe! trussa! hale in the brayles!

Thow halyst net, be god, thow fayles!

O se howe welle owre good shyp sayles!»

36 And thus they say among.

«Hale in the wartake!» «hit shal be done.»

«Steward! couer the boorde anone,

And set bred and salt therone,

40 And tary net to long."

Then cometh oone and seyth, «be mery,

Ye shall haue a storme or a pery."

«Holde thow thy pese! thow canst no whery,

44 Thow medlyst wondyr sore»

Thys mene whyle the pylgryms ly,

And haue theyr bowlys fast theym by,

And cry aftyr hote maluesy,

48 «Thow helpe for to restore.»

Ffor they myght ete neyther sode ne rost;

And som wold haue a saltyd tosst

A man myght sone pay for theyr cost,

52 As for oon day or twayne-

Som layde theyr bookys on theyr kne,

And rad so long they myght not se;»

«Allas! myne hede wolle cleue on thre!»

56 Thus seyth another certayne.

Then commeth owre owner lyke a lorde.

And speketh many a royal worde,

And dresseth hym to the hygh borde,

60 To see alle thyng be welle

Anone he calleth a carpentere,

And byddyth hym bryng with hym hys gere,

To make the cabans here and there,

64 With many a febylle celle; 
A sak of strange were there ryght good,

Ffor som must lyg theym in theyr hood;

I had as lefe be in the wood,

68 Without mete or drynk;

For when that we shall go to bedde,

The pumpe was nygh oure beddes hede,

A man were as good to be dede

72 As smell therof the stynk!

ANÁLISIS

La composición de esta canción se asemeja en la forma a la balada tradicional. Consta de nueve estrofas divididas cada una de ellas en dos cuartetos. La medida no es regular y la rima de cada estrofa se ajusta al tipo $a a a b, c c c b$, si bien, en más de una ocasión, parece algo forzada, tanto en el uso del vocabulario, como en la estructuración sintáctica:

«among-long», «ny-by», «mery-whery», «ly-theym by», «twayne-certayne», «welle-celle», "good-hood", etc.).

Conviene recordar a este respecto que la lengua inglesa del siglo $\mathrm{XV}$ se había alejado del tipo de estructuración sintáctica característica del inglés antiguo y que, por lo tanto, se hallaba ya más próxima a la del inglés moderno que a la de aquél. Prácticamente desaparecido el sistema casual de los nombres y notablemente simplificados los paradigmas pronominales, la estructuración de la frase se hace cada vez más rígida, dando lugar al modelo básico S-V-O. Por otra parte, conviene señalar que la ortografía de este poema es bastante inconsistente, si exceptuamos el empleo de la $y$ griega en vez de la $i$ latina, debida a la influencia de los amanuenses anglonormandos.

Los copistas medievales se enfrentaban a menudo con textos que habían sido escritos en un dialecto distinto del suyo propio. Tenían que elegir entre copiarlo en el dialecto original o transponerlo al suyo propio. En este caso, las dificultades eran considerables, puesto que no sólo tenían que transponer los grafemas, sino también los fonemas. Y estas dificultades no siempre se resolvían airosamente. Hay que decir también que los errores se infiltraban incluso en el caso de copiar textos escritos originariamente en el mismo dialecto que el del amanuense, bien porque el original llegaba con errores, o porque los cometía el copista. Finalmente, no son pocos los casos en los que aquél decidía introducir alguna modificación, incluso a costa de la rima o de la medida. Esta fal- 
ta de uniformidad en el uso de la ortografía es uno de los rasgos dominantes en el período del inglés medio.

A finales del siglo XIV, como lo demuestran la medida y la rima, la $\boldsymbol{e}$ final a menudo se pronunciaba todavía. En Chaucer, por ejemplo, Rome rima con to me, workis con clerk is, goon the con youthe. En términos generales puede decirse que a finales del siglo $\mathrm{XV}$ esta $-\boldsymbol{e}$ final desaparece casi por completo de la pronunciación y que en el siglo XVI también de la ortografía, si exceptuamos la denominada por algunos la -e de los amanuenses. La falta de uniformidad e imprecisión en los usos de esta $\boldsymbol{e} \boldsymbol{e}$ final es la que indujo a los poetas ingleses del siglo XVII a creer que muchos versos de Chaucer eran cojos, creencia que se mantuvo hasta que en 1775 el erudito J.R.Tyrwhitt demostró que esa $\boldsymbol{e} \boldsymbol{e}$ final formaba parte de la medida y de la rima en multitud de ocasiones y que, ese era el caso de la poesía de Chaucer. En cuanto al poema The pylgryms Sea-Voyage and Seasickness es evidente que su autor utilizó esta - $e$ final para rimar sus versos.

A continuación señalamos, por estrofas, los contenidos que nos han parecido más significativos.

1. En los dos cuartetos de la primera estrofa se repite la misma idea: las tribulaciones que aguardan a los pasajeros. En la primera se menciona el punto de destino y en la segunda, el de partida, sin que éste pueda en modo alguno variar el pronóstico respecto a la suerte de los peregrinos que se embarcan.

2. En la segunda estrofa, son las voces de mando con las que el jefe impone por las bravas su autoridad, lo que, de alguna manera, contribuye al malestar de los pasajeros. Conviene tener presente el tamaño de las embarcaciones de aquellos tiempos en las que la escasez de espacio debía ser la nota habitual.

3. En la tercera, se describen las diversas acciones de los marineros, introduciéndose la ironía en el segundo cuarteto, pues es más que dudoso que cuando más de uno estaba ya mareado, tuviera deseos de jugar para distraerse:

Some are lyke to cowgh and grone (verso 23)

4. Y llegamos a la cuarta estrofa en la que se mezclan las órdenes a los marineros para que realicen sus faenas, al tiempo que se le pide al cocinero que prepare la comida, referencia igualmente burlona si se tiene en cuenta que los peregrinos no tenían ganas de comer:

Our pylgryms haue no lust to ete., (verso 27) 
En el segundo cuarteto se refuerza la misma intención irónica al mencionarse la bebida.

5. En la quinta estrofa el narrador utiliza idéntica técnica. Al camarero se le ordena ahora que prepare la mesa, sin olvidar el pan y la sal.

6. Aquí se introduce un nuevo elemento de «torture» para los pobres pasajeros a quienes un marinero les anuncia que se acerca una borrasca, después de invitarles a que se alegren: ("be mery», verso 41) y que mantengan la calma, pues no hay otro remedio:

Holde thow thy pese! thow canst no whery, (verso 43)

En el segundo cuarteto de esta sexta estrofa se nos describe el estado lamentable en que se encuentran los sufridos peregrinos que yacen por el suelo con el estómago en la boca:

...haue theyr bowlys fast theym by, (verso 46$)$

7. Con igual ironía nos cuenta el narrador que más de uno estaría dispuesto a tomarse una tostada salada:

...som wold haue a saltyd tost, (verso 50)

En el segundo cuarteto de la séptima estrofa se comenta que lo único que pueden hacer los pasajeros es leer. Uno de ellos manifiesta que le va a estallar la cabeza en tres pedazos.

8. Por fin, el poeta narrador se incorpora al pasaje de forma explícita mediante el empleo de expresiones como "...owre owner...." que aparece por primera vez en el verso 57. Es cierto que la forma owre se emplea no pocas veces en sentido impersonal, pero, aun aceptando que ese fuera el sentido del posesivo en este contexto, no cabe dudar más de la presencia del narrador cuando dice:

I had as lefe..., (verso 67), we shall go.... (verso 69),

the pumpe was nygh oure beddes hede, (verso 70)

De fina ironía pueden juzgarse asimismo las expresiones que aparecen en el primer cuarteto de la octava estrofa:

...lyke a lorde

and speketh many a royal worde,

and dresseth hym... 
9. Como ocurre a menudo en este tipo de composiciones poéticas, el narrador manifiesta, por fin, su propio punto de vista, pasando de la descripción objetiva, más o menos aséptica, a la crítica. Así, en la última estrofa pone claramente de relieve el decepcionante contraste entre las preocupaciones del patrón, a quien sólo parece interesarle su barco, y el total desinterés por los pasajeros que no disponen ni siquiera de un saco de paja para acostarse, que tienen que hacerlo medio vestidos y que, por si todo lo dicho no fuera suficiente, tenían que soportar el hedor procedente del sumidero que, para colmo, estaba junto a la cabecera de sus supuestas camas.

En estas dos últimas estrofas desaparecen definitivamente los entrecomillados. No se trata ya de reproducir el discurso del "masty' $r$, del 'steward", de los marineros o de los «remenaunts». Se trata de justificar las advertencias que el poeta narrador les había hecho a los peregrinos, en el inicio mismo de su argumentación, sobre lo que les esperaba en su viaje a Santiago. Es de señalar también la total pasividad en que aparecen sumidos los viajeros como el procedimiento más eficaz para mostrar la desvalidez y el sometimiento de aquéllos frente a los rigores del viaje, las burlas de los marineros y la indiferencia del patrón. A todo esto han quedado reducidas la alegría, la algazara, las expectativas y las ilusiones de aquéllos que un día decidieron embarcarse rumbo a Compostela.

TRADUCCIÓN. Se ha intentado respetar, en la medida de lo posible, la literalidad del original.

«iPasajeros, olvidaos de toda diversión!,»

pues muchos de los que van a Santiago

empiezan a sentirse mal,

nada más comenzar a navegar.

Tan pronto se hacen a la mar, ya sea desde Sandwiche o desde Wynchylsee., desde Bristol o desde dondequiera que sea, empiezan a desfallecer.

En seguida se oyen las roncas voces de mando a los marineros para que, rápidamente, se sitúen en torno al mástil y preparen las jarcias y las poleas, con gritos de «iArriba, arriba!» «Vamos, muchacho, arriba!», 
«Tú, quítate de en medio,»

Los oficiales se imponen con autoridad.

Uno o dos chavales se encaraman rápidos,

A ambos lados yace el velamen;

¡»Arriba las velas»! gritan los demás,

mientras tiran con todas sus fuerzas.

«Contramaestre, prepara rápidamente el barco,

para que los peregrinos puedan distraerse;

pues antes de que llegue la noche,

más de uno estará ya mareado y gimiendo.»

« ¡Tirad de la soga! ¡Vamos, soltad la maroma!

¡Cocinero, prepáranos rápidamente la comida, aunque los peregrinos de comer ganas no tienen!»; «Que Dios les dé un buen descanso!» «Al timón!,» y no te dejes llevar por el viento.

« ¿Camarero, tío, una jarra de cerveza!»

«En seguida, señor, con mis mejores deseos, y que lo disfrute, como si fuera la última vez»

« Vamos, rápido, tirad de las cuerdas!

Chaval, tú no estás tirando, me estás fallando

¿Qué bien navega nuestro barco!»

Eso dicen los marineros.

«Tira del aparejo hacia dentro!»

«iHay que hacerlo así!»

“Camarero, rápido! el mantel, el pan y la sal.

«Anda, vamos, no te eternices!».

«Alegraos; se nos echa encima una borrasca.»

«iMantened la calma!

No hay más remedio.

No os amarguéis inútilmente.»

Los pobres peregrinos yacen tirados por el suelo

y con el estómago en la boca.

Piden a gritos un trago de malvasía caliente.

y que les auxilien para reponerse.

Más de uno se comería una tostada salada,

pero no aguantaban ni los hervidos ni los tostados; 
y eso que alguno había pagado ya por adelantado

el importe por uno o dos días.

Algunos se ponían un libro sobre las rodillas,

y leían hasta que ya no veían;

«Ay mi cabeza! ¡se me va a romper en pedazos!»

Así quejábase otro peregrino.

Entonces se acerca el jefe con aires de caballero

$y$, hablando con lenguaje de reyes,

se dirige a la borda

para comprobar si todo está en regla.

Seguidamente llama a un carpintero,

y le ordena que se traiga el equipo

para arreglar, aquí y allá,

los muchos desperfectos de las cabinas.

Ni siquiera un saco de paja para dormir;

algunos tienen que echarse con la capucha puesta.

Aun sin comida ni bebida,

mejor estarían perdidos en medio de un bosque.

$Y$ cuando nos íbamos a la cama,

el desagüe, junto a la cabecera,

olía tan mal, tan mal que habría bastado

para acabar con el más «pintao».

\section{Be mery,}

Podría muy bien tomarse esta expresión como referencia a una de las tradiciones más arraigadas de la poesía medieval inglesa, como lo es el tema recurrente de «la joie de vivre», que se relacionaba de modo especialmente llamativo y entusiásticamente fogoso con el mes de abril, el mes con el que se iniciaba el año medieval. Recordemos que es también el primer mes de embarazo de María, ya que la fiesta de la Anunciación es, precisamente, el 25 de marzo y que en la Edad Media se contaba como el día de Año Nuevo. La primavera era, pues, la época de la renovación, del explosivo y fastuoso renacer de la naturaleza en todas sus formas. Desde el punto de vista religioso señalaba el comienzo de una nueva era para la redención del hombre. En el hermoso poema de principios del siglo XV, I sing of a maiden, podemos observar que en las estrofas 2,3 y 4 , de las 5 que lo forman, aparece la pala- 
bra abril, en clara referencia a dicha tradición literaria. Veámoslo en la estrofa 2, que dice:

«As dew in Aprille

That falleth on the grass.

As dew in Aprille

That falleth on the flown.

As dew in Aprille

That falleth on the spray.

(como escarcha de abril

que cae sobre la hierba, como escarcha de abril que cae sobre la tierra, como escarcha de abril que cae sobre la yema).

Pero la asociación de la primavera con el resurgir del amor, tan común en los escritores de la Edad Media, es igualmente característica de la poesía amorosa secular, como puede apreciarse perfectamente en el primer verso de la primera estrofa de un poema del siglo XIII o principios del XIV, que es, sin duda, otra clara referencia a dicha tradición literaria.

Betwene Mersh and Averil,

When spray beginneth to springe,

The lutel fowl hath hire will

On hire lud to singe.

Ich libbe in love-longing

For semlokest of alle thinge,

He may me blisse bringe;

Ich am in hire baundoun.

(Entre marzo y abril, cuando las yemas empiezan a abrirse, el pajarillo cumple su deseo

y canta su canción.

Ardo en deseos de amar

A la más hermosa de todas;

puede traerme la felicidad;

pues estoy rendidamente enamorado). 
O en el poema popular menos convencional del siglo XV, Besse Bunting:

In Aprell and in May,

When hartes be all mery,

Besse Bunting, the millaris may,

Withe lippes so red as chery,

She cast in hir remembrance

To passe hir time in daliance

And to leve hir thought driery.

Right womanly arayd

In a peticote of whit,

She was nothing dismayd

Hir countenance was full light.

(En abril y mayo,

cuando se alegran los corazones,

Besse Bunting, la chica del molinero,

con los labios rojos como la amapola,

deja a un lado sus recuerdos

para pasar el tiempo en amoríos

y huir así de sus tristes pensamientos.

Cumplidamente ataviada como mujer, con una falda blanca,

ya no estaba apocada

y su actitud era muy desenvuelta).

Chaucer no fue, ni mucho menos, una excepción a esta tradición literaria. Con admirable acierto asocia el retoñar de la vida, tan evidente en la naturaleza, con el mundo interior del individuo. Así lo manifiesta en los primeros versos de su Prologue to the Canterbury Tales:

Whan that Aprill with hise showres soote

The droghte of March hath perced to the roote,

And bathed every veine in swich licour,

Of which vertu engendred is the flour.

(Cuando llegan los aguaceros de abril,

las lluvias de marzo han penetrado ya hasta la raíz

e impregnado cada vaso con ese vivificante elixir

que tiene el poder de engendrar la flor). 
La primavera es, pues, la estación de la fertilidad. Con la lluvia y el calor vuelve la vida a la naturaleza, tal y como se describe certeramente en ese encantador poemita del siglo XIII Sumer is icumen in, en el que la palabra "sumer» no es más que otra forma de designar la primavera, como lo indica obviamente su contenido.

Sin embargo, en el poema que hemos comentado, no hay ni una sola referencia al tiempo en el que se supone va a iniciarse el Sea-Voyage. A decir verdad, tampoco era necesario, dado su tono intemporal. Nada impide, por tanto, pensar que la partida tuviera lugar en primavera, aun cuando fuera compuesto para ser cantado o recitado a cualquier grupo de peregrinos, independientemente de la fecha de su salida. Por eso, con el fin de realzar, por contraste, el tono burlón de la Canción del marinero, he querido imaginar que se recitó a un grupo de peregrinos que se embarcaban por primera vez para España en la estación florida, que es cuando brota con vehemencia ese deseo romántico de To goon on pilgrimages o cuando los "palmeres» se embarcan for to seken straunge strandes, como nos cuenta Chaucer en su Prólogo. 